\title{
Immediate one-step flapless placement of two-piece dental implants with and without grafting
}

\section{Background}

It is already demonstrated that one step approach immediate after teeth extractions have lots of advantages upon two-steps one. A widely discussed theme remains the necessity of grafting the buccal space between implant and cortical plate, especially in cases when the buccal wall of the socket is intact.

Aim

To appreciate the influence of the grafting material usage in case of one step flapless placement of two piece dental implants immediate after teeth extractions ir esthetic zone.

\section{Matherial and methods}

Ninety five two-piece dental implants (Dentium superline) were inserted in 44 patients $(46 \pm 1,74$ years) after teeth extraction in the esthetic zone using one step flapless approach. All the implants have been placed close to the palatal bone, creating a space between the buccal bone and implants surface. In the study group, 49 implants were placed without grafting materials (Figure 1). In the control group, 45 implants were installed and collagen/hydroxyapatite grafting material were used to fill the buccal space (Figure 2). In both groups, when insertion torque shifted $30 \mathrm{Ncm}$, temporary crown were delivered. According to the orthopantomogram, implants' sides were divided into anterior and posterior ones. The following parameters were evaluated: primary and secondary stability (Periotest Classic), periimplant bone modeling ( 1 year follow-up). Statistical analysis was made by calculating mean values, standard errors, indices of Student's paired $t$ test and MannWhitney U tests.

\section{Results}

Primary stability was $-3,67 \pm 0,149$ (Study) and $-3,84 \pm 0,21$ (Control) while the secondary were $-6,44 \pm 0,148$ (Study) and $-6,33 \pm 0,188$ Control (primary vs secondary, $\mathrm{p}<0,001)$. In the Study Group, the periimplant bone loss at mesial and distal aspects were: $0,73 \pm 0,157 \mathrm{~mm}$ and $0,61 \pm 0,163 \mathrm{~mm}$ during healing period; $0,37 \pm 0,105 \mathrm{~mm}$ and $0,33 \pm 0,062 \mathrm{~mm}$ at 1 year follow up. In the Control Group, the periimplant bone loss at mesial and distal aspects were: $0,6 \pm 0,163 \mathrm{~mm}$ and $0,68 \pm 0,152 \mathrm{~mm}$ during period; $0,34 \pm 0,11 \mathrm{~mm}$ and $0,3 \pm 0,2 \mathrm{~mm}$ at 1 year follow up. The evaluation of soft tissue profile did not reveal any shrinkage from buccal aspect in the study group after 1 year. There was no statistical difference between bone loss of both groups, neither during healing, nor 1 year post-prosthetic. A statistical difference has been observed between bone loss values of supracrestal implants position versus subcrestal ones ( $p<0,01$ for mesial and $p<0,05$ for distal aspects) with lowest values in supracrestal position.

\section{Conclusions}

The lack of bone loss difference between groups demonstrates that in case of immediate implant placement and intact buccal socket wall bone grafting material usage is not necessary. The relation between the implant platform (microgap) and bone crest has a significant impact upon periimplant bone modeling, supracrestal position showing lowest bone loss values. The summary bone loss from the placement to 1 year follow up does not exceed values described in the literature for other implant types.
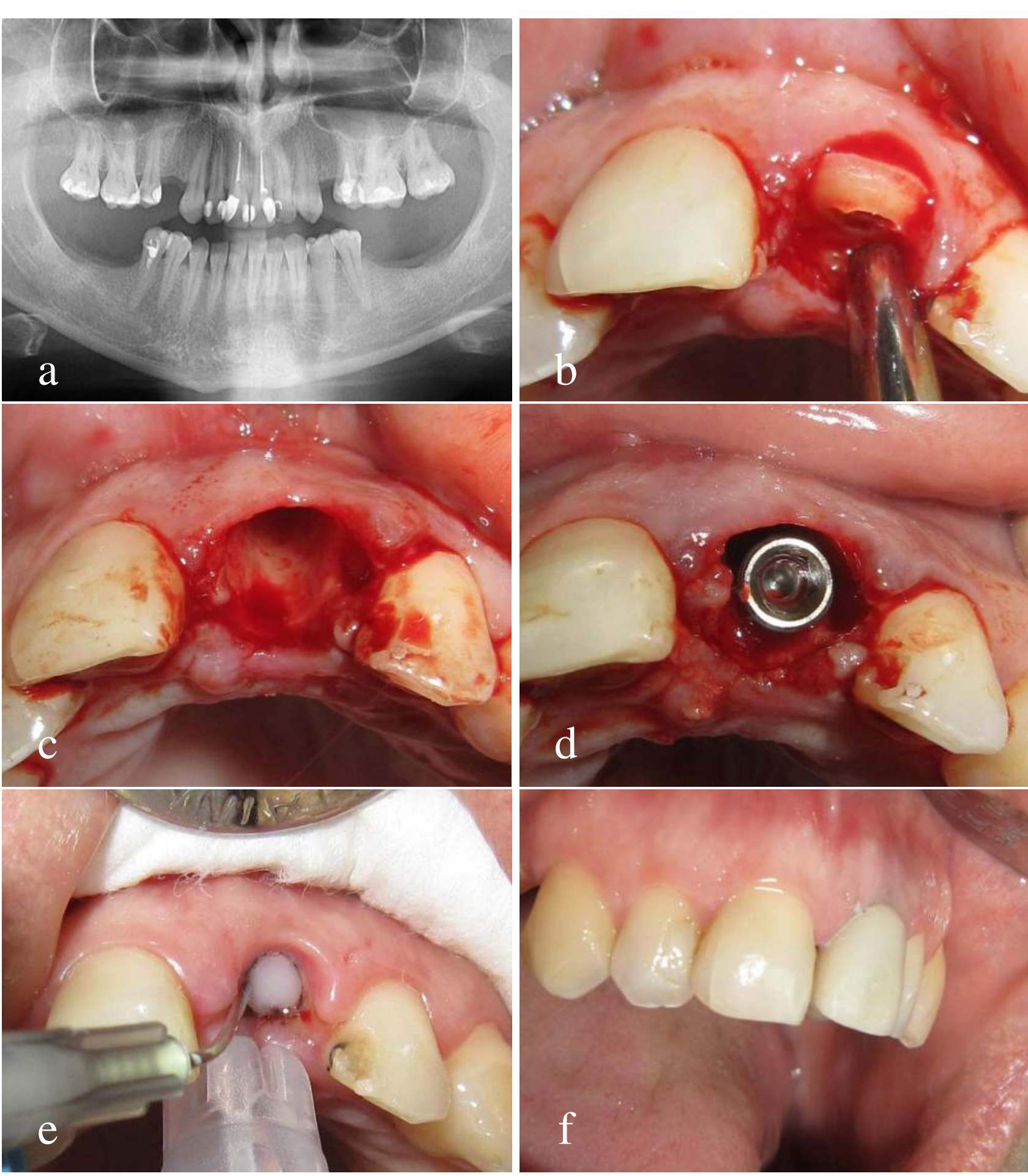

Figure 1. Patient B: preoperative OPG (a), intraoral view during extraction (b); socket preparation (c); implant placement without grafting (d); antiseptic preparation of the platform after 7 days prior to provisional fixation (e); temporary crown at 7 days postoperative repeats the form of previous tooth, without occlusal contacts (f).
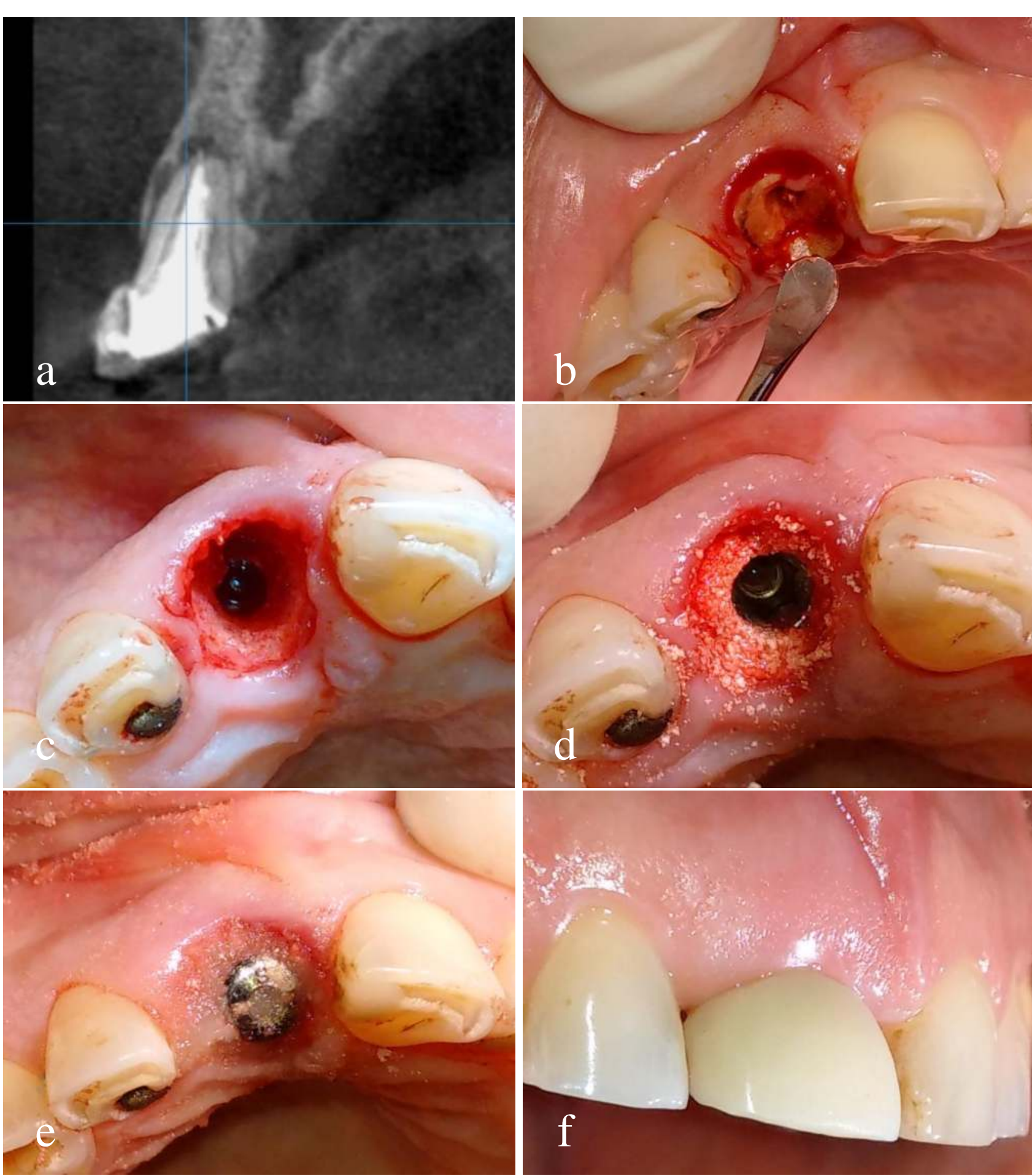

Figure 2. Patient A: preoperative CBCT fragment (a), intraoral view during extraction (b); socket preparation (c); implant placement and grafting (d); healing abutment connection and isolation gel appliance (e); temporary crown at 7 days postoperative repeats the form of previous tooth, without occlusal contacts (f) 